\title{
Establishment of a Modulus Measurement Method in Denture-supporting Tissue using an Intraoral Simultaneous Measurement System and Finite Element Analysis
}

\author{
${ }^{1}$ Naoya Takamatsu, ${ }^{2}$ Yuji Sato, ${ }^{3}$ Noboru Kitagawa, ${ }^{4}$ Osamu Shimodaira, ${ }^{5}$ Akio Isobe, ${ }^{6}$ Satomi Tanaka, ${ }^{7}$ Tomoka Omori
}

\begin{abstract}
Aim: A three-dimensional finite element analysis (3D FEA) study for measuring optimum elasticity using thickness and load data collected from elderly edentulous patients when feeling pressure-related pain.

Materials and methods: Tested elasticity as in a previous report ("measured elasticity") is measured using an able FEA ("optimum elasticity"). A two-way analysis of variance (ANOVA) was performed and Pearson's correlation coefficients were obtained. Pearson's correlation coefficients were also determined for thickness $(\mathrm{mm})$, measured elasticity, and optimum elasticity (MPa) in different experimental areas. Finally, the von Mises stresses and subsidence $(\mathrm{mm})$ results of the FEA were tested using measured elasticity; those using optimum elasticity were measured with a two-way ANOVA.
\end{abstract}

Results: Seventeen patients were studied. Optimum elasticity was significantly lower than measured elasticity $(p<0.05)$. Correlations were found in all three palatal areas $(p<0.01)$. A correlation between thickness and measured elasticity was found at the midpoint $(p<0.05)$ but not at the median or lateral sections. No correlation between thickness and optimum elasticity was found in any of the three palate areas. Finite-element analysis results using measured elasticity indicated no differences in von Mises stress at any site when compared with FEA results using optimum elasticity. Subsidence was significantly smaller $(p<0.05)$.

Conclusion: It is difficult to estimate elasticity using the thickness of denture-supporting tissue and necessary to optimize elasticity in all palatal areas when using an FEA. We established a method to measure elasticity.

Clinical significance: If it were possible to optimize elasticity in a 3D FEA of maxillary denture-supporting tissue, it would become possible to design an optimal relief area through simulation. This would reduce the burden on the patient, such as the need for adjustment after wearing dentures, and improve quality of life.

Keywords: Complete maxillary dentures, Denture-supporting tissue, Elasticity, Finite element analysis, Mucosa.

\footnotetext{
${ }^{1-7}$ Dentist

${ }^{1-7}$ Department of Geriatric Dentistry, Showa University, Ota-ku Tokyo, Japan

Corresponding Author: Naoya Takamatsu, Dentist, Department of Geriatric Dentistry, Showa University, Ota-ku, Tokyo, Japan Phone: +9181337871151, e-mail: n.takam@dent.showa-u.ac.jp
}

How to cite this article: Takamatsu N, Sato Y, Kitagawa N, Shimodaira O, Isobe A, Tanaka S, Omori T. Establishment of a Modulus Measurement Method in Denture-supporting Tissue using an Intraoral Simultaneous Measurement System and Finite Element Analysis. Int J Prosthodont Restor Dent 2018;8(1):3-9

Source of support: This work was supported by a 2014 to 2016 Grant-in-Aid for Scientific Research (Basic Research C Grant No. 26462935).

\section{Conflict of interest: None}

\section{INTRODUCTION}

In the super-aged Japanese society, the demand for dental prosthetic treatment has been increasing. ${ }^{1}$ When providing dental prosthetic treatment to elderly patients, it is extremely important to understand the age-induced physiological and morphological changes in the oral mucosa. In this regard, there have been various studies on the thickness of denture-supporting tissue, ${ }^{2-4}$ viscoelasticity, $^{5-7}$ and pain. ${ }^{8-12}$ Thus, a system was invented that uses a strain gauge attached to an ultrasonic thickness gauge to simultaneously measure changes in oral mucosa thickness and load until pain was felt by a patient at chairside. ${ }^{13}$ In the present study, the relationships between thickness, elasticity (mucosal property parameters), pressure, subsidence, and compressibility (pressure/pain threshold parameters) were examined, when pain was felt in the palatal mucosa of young dentulous ${ }^{14}$ and elderly edentulous subjects. ${ }^{15}$ It was found that although it was possible to estimate subsidence using the thickness and elasticity of the palatal mucosa, in elderly edentulous patients, it was difficult to simply estimate the pressure pain threshold from the thickness for various reasons. Therefore, to further understand clinical applications of prosthodontics, the authors of present study believed it was necessary to test loads with real denture bases rather than probes.

A 3D FEA is an appropriate method to explore the complex biomechanics of denture-supporting tissue. First, 3D FEA allows estimations of the dynamic response within objects, which is rarely realized in other experiments. In one single test, 3D FEA is capable of providing 
multiple types of physical data, including stress, distortion, and displacement. Compared with other biomechanical experiments, the conditions for 3D FEA tests are relatively easy to set. In the field of dentistry, using 3D FEA to analyze internal stresses and strains in dentures and denture-supporting tissue has already become a mainstream method in biomechanical analysis. ${ }^{16-18}$

Thus far, whenever a 3D FEA method is appropriate, researchers have used devices to add pressure to denturesupporting tissue mechanically to measure and calculate the elasticity used in constructing their approximate 3D FEA models of living humans. ${ }^{19,20}$ However, there has been no investigation on whether such an elasticity measurement works in cases of real human bodies.

The present study was undertaken to examine a 3D FEA method of measuring elasticity that optimizes a model of denture-supporting tissue using thickness and load data collected from elderly edentulous patients when pressure/pain was first perceived.

\section{MATERIALS AND METHODS}

The subjects included in this study were wearing complete maxillary dentures and had healthy palatal mucosa. Both the thickness of the palatal mucosa and load changes until pressure/pain was felt by elderly edentulous patients were measured using the device invented and improved by Takeuchi et $\mathrm{al}^{13}$ and Isobe et $\mathrm{al}^{14}$ that simultaneously measures mucosa thickness and load. The device is an ultrasonic thickness gauge (25DL Plus; Olympus NDT Japan Inc., Japan) with a strain gauge (KFG-5-120-C1-11L1M3R; Kyowa, Japan) attached to its probe (hereafter referred to as the "probe"). Moreover, experiments were carried out in three areas of each patient's maxillary palatal mucosa: The median part of the palate (1), the lateral part of the first molar (3), and the midpoint between these two parts (2) (Fig. 1). ${ }^{15,21}$
The preloaded "thickness" (T) of the palatal mucosa and hardness, as indicated by the "elasticity" (E) (hereafter referred to as "measured elasticity"), are mucosal property parameters. "Subsidence" (S), which is the change in mucosal thickness, "pressure" $(\mathrm{P})$, which is the pressure when pain is first perceived, and "compressibility" (C), which is the rate of pressure change, are parameters of the pressure/pain threshold. Measured elasticity is calculated using the following equation:

$$
E=P / C \times 100
$$

$\mathrm{P}=$ pressure $(\mathrm{MPa}) ; \mathrm{C}=$ compressibility $(\%) ; \mathrm{E}=$ measured elasticity (MPa)

The probe forms were captured by a 3D scanner (One-Shot 3D Measurement VR-3100; Keyence, Japan) and constructed into a 3D FEA model (hereafter referred to as the "FEA model") using 3D FEA software (Femap; Research Center of Computational Mechanics). The FEA models of denture-supporting tissue were constructed for all experimental parts in the shape of a rectangular cuboid with a base of $10 \times 10 \mathrm{~mm}$ and a height equal to the thickness of the subject's palatal mucosa. Meshes were constructed in the shape of cubes with sides equal to $0.1 \mathrm{~mm}$. The total number of nodes was about 250,000 at minimum and about 790,000 at maximum, and the total number of elements was about 230,000 at minimum and about 750,000 at maximum. In addition, both the probe and denture-supporting tissue were simulated as homogeneous, isotropic, linear, elastic structures.

Referring to the report by Sato et $\mathrm{al}^{22}$ this study set the elasticity of the FEA probe model at 3,000 MPa and Poisson's ratio at 0.34 . Poisson's ratio in the FEA model of denture-supporting tissue was set at 0.4 (Table 1).

The load was applied to the FEA model of denturesupporting tissue at the median part of the palate, lateral part of the first molar, and the midpoint between these two parts. A load equal to that when pain was first
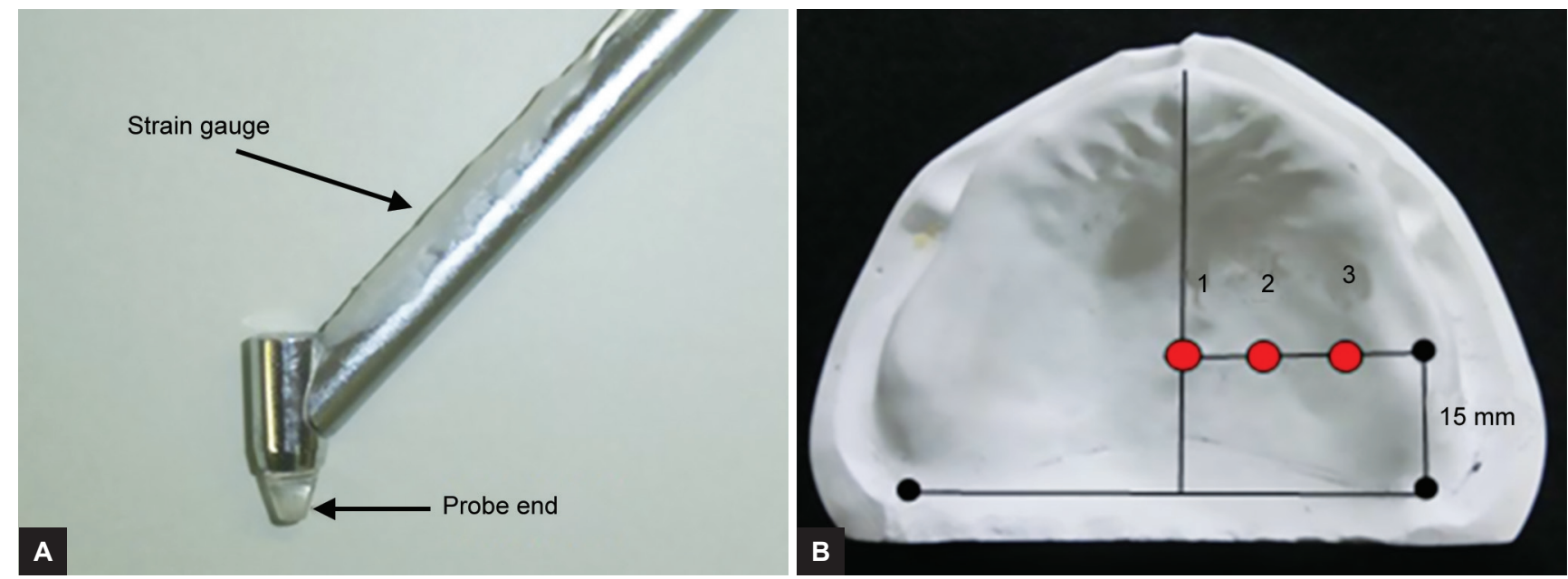

Figs $1 \mathrm{~A}$ and B: Simultaneous intraoral measurement system. Experiments were carried out in three areas of each patient's maxillary palatal mucosa: the median part of the palate (1), the lateral part of the first molar (3), and the midpoint between these two parts (2) 
Table 1: Values for the physical properties in the FEA model

\begin{tabular}{lll}
\hline Materials & $\begin{array}{l}\text { Elastic modulus } \\
(\mathrm{MPa})\end{array}$ & $\begin{array}{l}\text { Poisson's } \\
\text { ratio }\end{array}$ \\
\hline Probe & 3,000 & 0.34 \\
Denture-supporting tissue & Optimum value & 0.4 \\
\hline
\end{tabular}

perceived by subjects as measured by Kotani et al ${ }^{15}$ was applied vertically at each point.

In an FEA, the accuracy of the simulation can be further improved through the subdivision of a complex domain into small elements, the inclusion of detailed load conditions and physical properties, and the introduction of time elements in a nonlinear dynamic analysis. However, adding settings that are more detailed will inevitably lead to a longer analysis duration. In the industrial field, researchers often simplify details and use an FEA as a "first-order analysis" at the initial stage of model design to better understand the larger picture. Our study, too, is a "first-order analysis" designed for the initial stage of a biomechanical analysis of denturesupporting tissue. ${ }^{23}$

Using the FEA model of denture-supporting tissue, we kept testing different elasticities and loads until the difference between the subsidence derived from Kotani et $\mathrm{al}^{15}$ measurement data and that given by the 3D FEA became smaller than 5\% (significance level, 95\%); and the elasticity when the difference first fell under $5 \%$ was considered the optimum elasticity.

The present study compared the measured elasticity with optimum elasticity, as well as their relations to the thickness of the palatal mucosa. Based on data from Kotani et al, ${ }_{15}^{15}$ the authors of present study studied the stress distribution through the subsidence of palatal mucosa and load change when pain was first perceived. In this study, it was assumed that pain was felt when occlusion led to subsidence of the denture, which in turn led to deformation of the denture-supporting tissue, so the analysis domain was limited to the domain where stress occurred because of deformation. Each subject's stress value in the domain that had the highest average von Mises stress that occurred at nodes and elements was chosen for analysis.

The FEA model of denture-supporting tissue using measured elasticity, analysis of the impact of subsidence, and von Mises stress were analyzed. Based on the data collected from 17 elderly edentulous patients in the study by Kotani et al, ${ }^{15}$ an earlier study from the department of authors of present study used the Shapiro-Wilk test to confirm the normality of each parameter for all experimental parts.

To compare measured elasticity and optimum elasticity, a two-way ANOVA conducted and Pearson's correlation coefficients were obtained. Pearson's correlation coefficients at all sites for thickness $\mathrm{T}(\mathrm{mm})$, measured elasticity $(\mathrm{MPa})$, and optimum elasticity $(\mathrm{MPa})$ were evaluated. Finally, a two-way ANOVA was performed on the von Mises stress and subsidence $(\mathrm{mm})$ of the 3D FEA results using measured elasticity and optimum elasticity separately. Statistical Package for the Social Sciences (version 19 PASW Statistics $19^{\circledR}$, IBM, Tokyo, Japan) software was used for statistical analysis.

\section{RESULTS}

Seventeen patients ( 8 men and 9 women; average age, 78.4 years) were enrolled for the study. Compared with measured elasticity, optimum elasticity was significantly less $(p<0.05)$ at the median part of the palate, lateral part of the first molar, and midpoint between the two parts. Moreover, a positive correlation $(p<0.01)$ was found at all three palatal parts where experiments were carried out (Graphs 1A to D).

Pearson's correlation coefficient showed a positive correlation $(p<0.05)$ between measured elasticity and thickness at the midpoint part, but no correlation was found at the median or lateral part. As for optimum elasticity and thickness, no correlation was found at any of the three parts (Graphs 1E to G).

The von Mises stress distributions of three subjects (whose denture-supporting tissue thicknesses were thinnest, thickest, and at the midpoint) are included in this report (Fig. 2).

There was no significant difference between von Mises stress obtained using measured elasticity and that obtained using optimum elasticity. However, subsidence obtained using measured elasticity was significantly less $(p<0.05)$ than that measured using optimum elasticity (Graph 2).

\section{DISCUSSION}

Significant stress was detected in the FEA model of denture-wearing mucosa at places corresponding to the contact point right underneath the probe and its edge. While it is natural that stress was detected right underneath the probe, we believe that stress occurred in both the axial and horizontal directions at the contact point of the probe in the FEA model of denture-wearing mucosa because of the viscoelastic property of mucosa and the impact of the shape of the probe tip edge. Optimum elasticity in the present study was much smaller than the measured elasticity because Kotani et $\mathrm{al}^{15}$ defined the load area as the area of the probe tip when calculating the measured elasticity, but the present study included both the tip area and other areas in the FEA model of denturesupporting tissue where stress occurred when the load of 

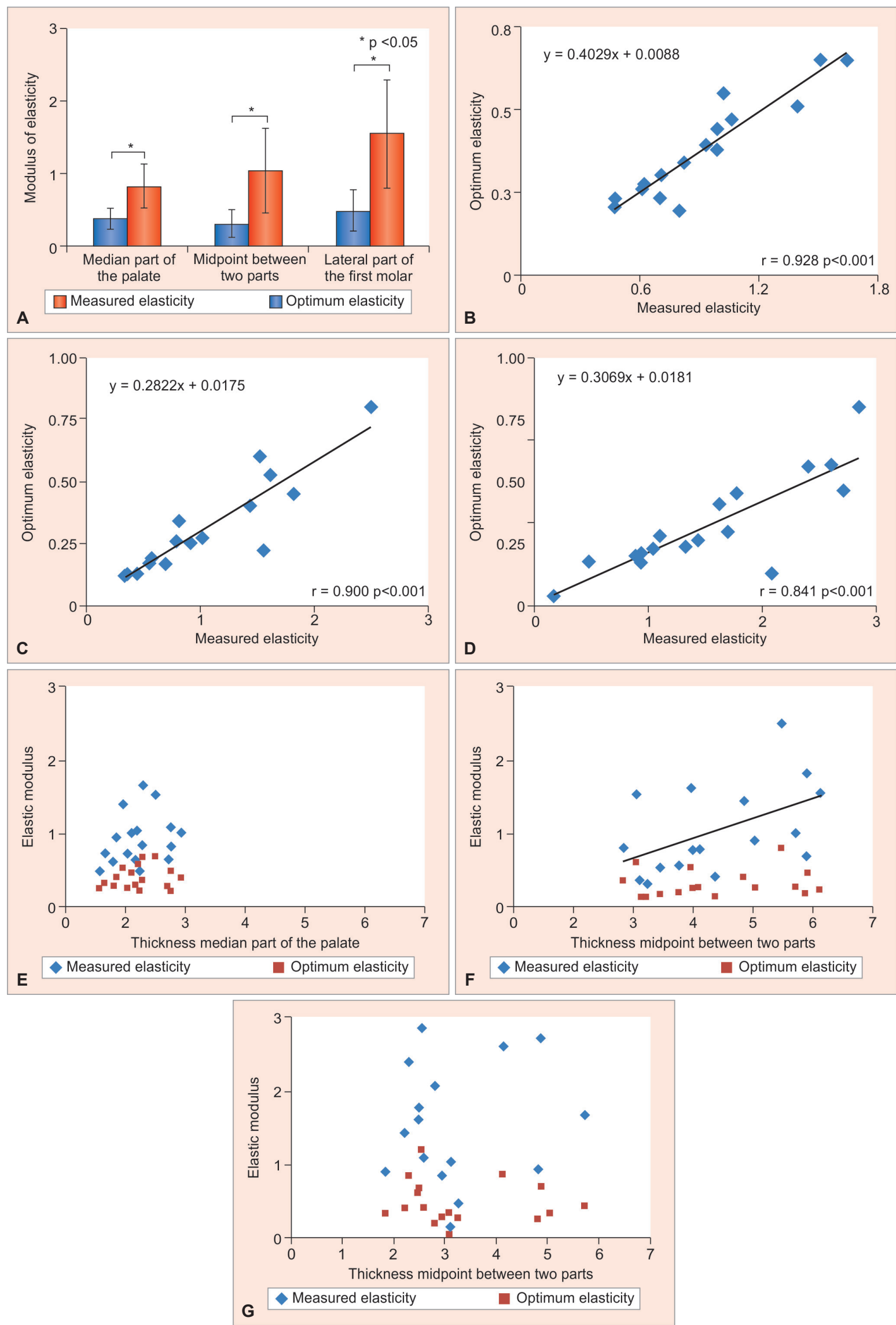

Graphs 1A to G: (A to D) Compared with measured elasticity, optimum elasticity was significantly less $(p<0.05)$ at the median part of the palate, lateral part of the first molar, and midpoint between the two parts. Moreover, a positive correlation $(p<0.05)$ was found. ( $E$ to $G)$ A correlation between thickness and measured elasticity was found at the midpoint part $(p<0.05)$, but not at the median or lateral part. A correlation between thickness and optimum elasticity was not found at any of three areas 

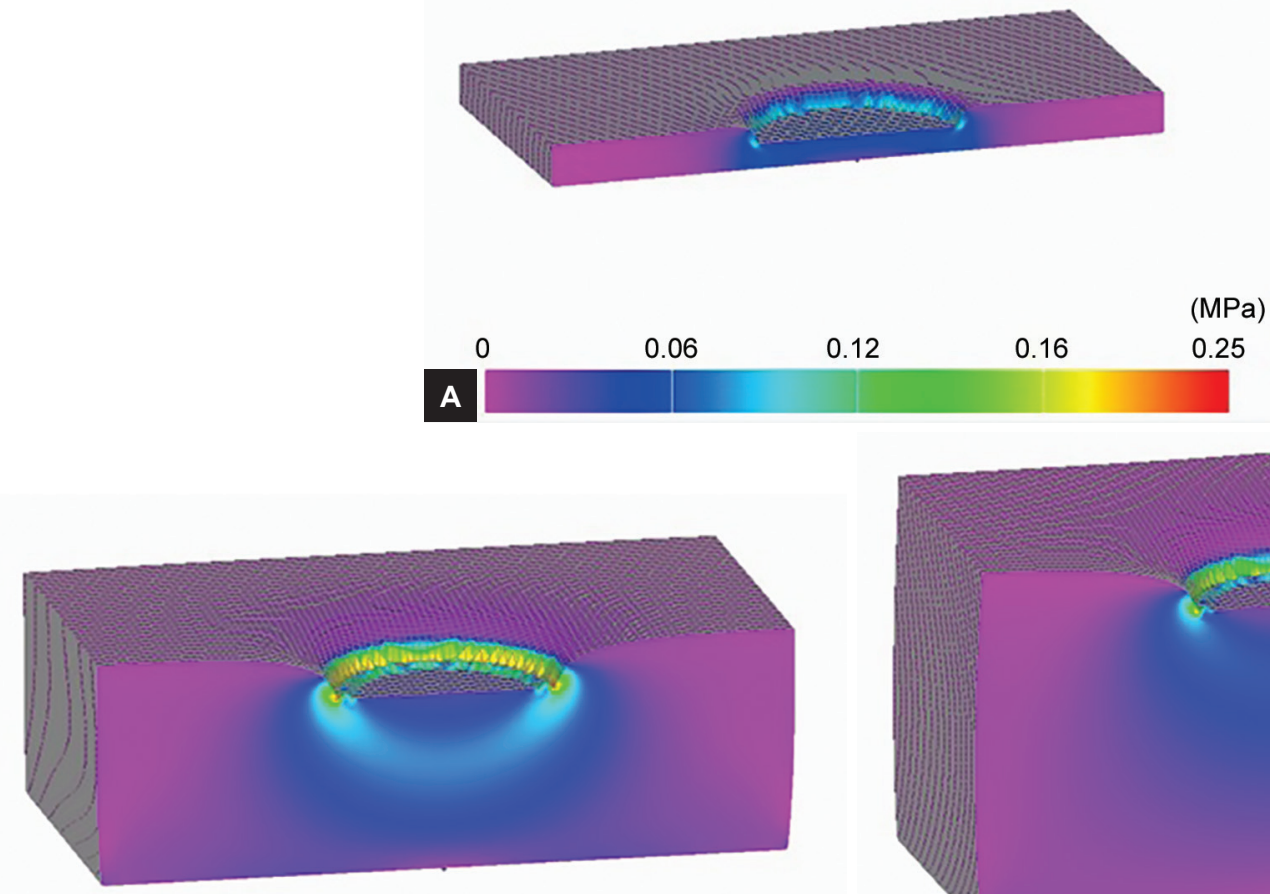

(MPa)

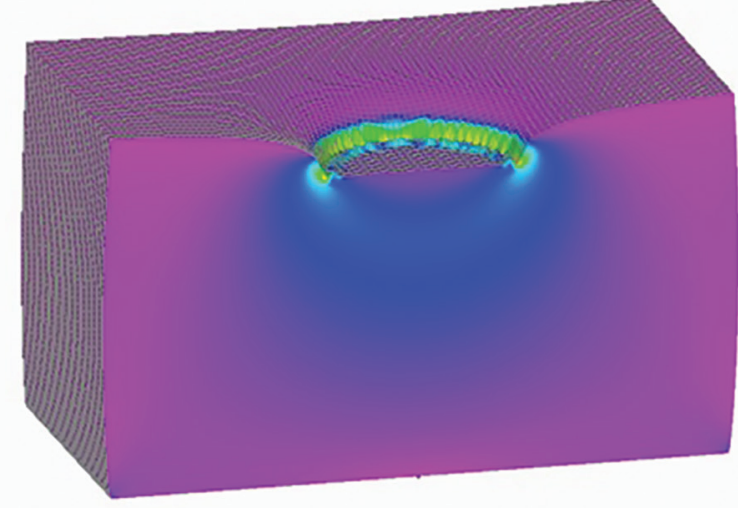

0

0.06

0.12

0.16

0.25

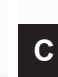

Figs $2 \mathrm{~A}$ to $\mathrm{C}$ : Minimum $(\mathrm{A})$, intermediate $(\mathrm{B})$, maximum $(\mathrm{C})$ thickness model
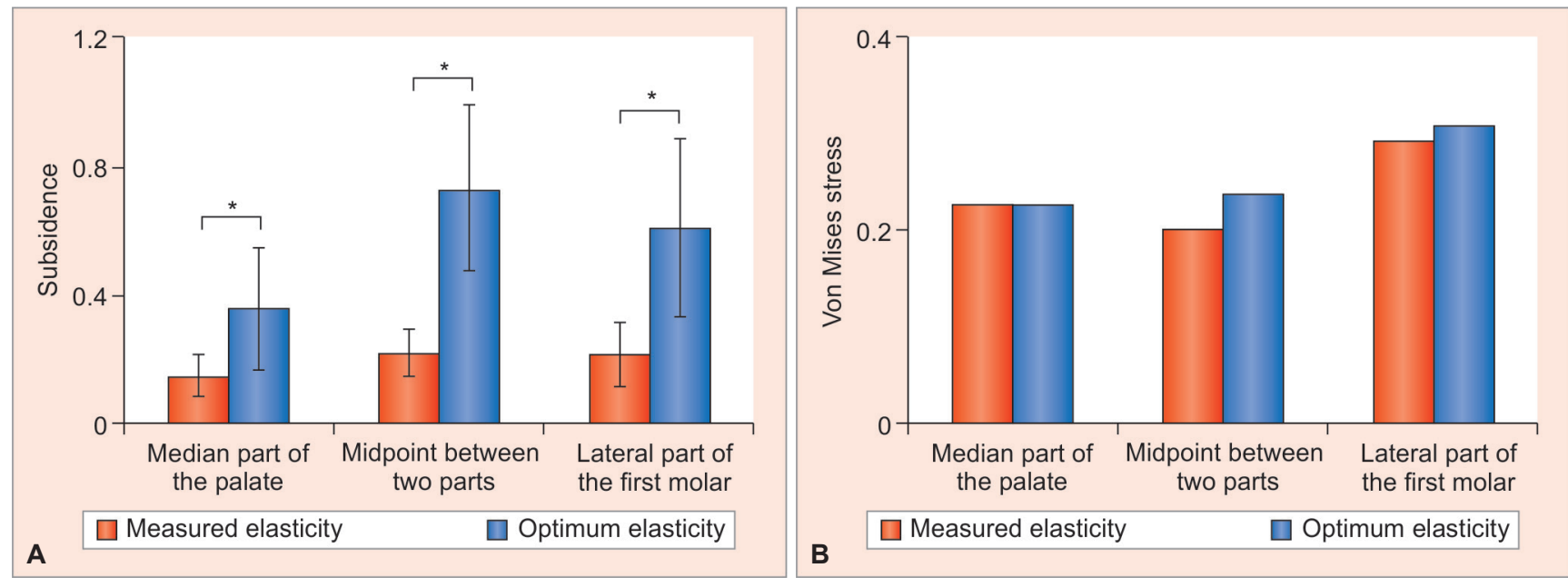

Graphs 2A and B: Finite-element analysis results using measured elasticity are not significantly different in the von Mises stress observed at all sites compared with FEA results using the optimal modulus; subsidence is significantly smaller $(p<0.05)$

the FEA model of the probe was applied when calculating optimum elasticity. Hence, because the pressure per unit area in the present 3D FEA study was smaller than that used by Kotani et al, ${ }^{15}$ optimum elasticity in the present study was significantly smaller than their measured elasticity. As measured elasticity and optimum elasticity are correlated, the authors of present study believed that it is possible to estimate optimum elasticity using measured elasticity.
A positive correlation $(\mathrm{p}<0.05)$ was found between measured elasticity and thickness at the midpoint part, but no correlation was found at the median or lateral part. As for optimum elasticity and thickness, no correlation was found at any of the three parts. In general, the epithelium of the oral mucosa is said to become thinner and more fragile along with aging. ${ }^{24}$ Akimoto $^{25}$ reported that the thickness of the mucosa near the mouth corners significantly decreases in people in their 60s to $90 \mathrm{~s}$. 
Shklar ${ }^{26}$ observed aging-related changes in the oral mucosa and reported that the oral mucosal epithelium obviously becomes thinner than that of young people. In addition, $\mathrm{Kohno}^{27}$ showed that the epithelial layer in denture wearers is thick and shows a trend of cornification as compared with no-denture wearers, whereas the epithelial layer is thinner and less cornified in no-denture wearers than denture wearers. These findings indicate that the oral mucosa becomes thinner by physiological aging, whereas it may become thicker by mechanical stimulation resulting from denture wearing. Further, according to Zarb et $\mathrm{al}^{28}$ the thickness and hardness (density) of the submucosal tissues play an important role in supporting dentures; when the submucosal tissues become thin, tissues lose elasticity. Moreover, Akimoto $^{25}$ reported that a decrease in adipose and glandular tissues and changes in the fiber alignment are the most important aging-related changes in submucosal tissues. Accordingly, the palatal mucosa in elderly edentulous subjects is considered to be less elastic and more prone to deformation by small loads, i.e., softer than the palatal mucosa in young dentulous subjects. Based on the above remarks, whereas it is possible to estimate measured elasticity using thickness for certain palatal parts, it is difficult to estimate optimum elasticity using thickness.

There was no significant difference between von Mises stress obtained using measured elasticity and that measured using optimum elasticity. Subsidence measured by 3D FEA using measured elasticity was significantly less $(\mathrm{p}<0.05)$ than that measured by 3D FEA using optimum elasticity. But in the Kanbara et $\mathrm{al}^{29}$ report, the elasticity is unified and it uses the measured elasticity. Accordingly, the present study states that an optimization of elasticity will affect the subsidence analysis result. Therefore, it is necessary to optimize elasticity to more accurately simulate the dynamic changes in denture-supporting tissue.

This study demonstrated the necessity to optimize elasticity when constructing FEA models of denturesupporting tissue. However, this conclusion was based on experiments carried out at selected parts of the palate. To fully understand the dynamics of denture-supporting tissue and the biomechanics of the pressure/pain threshold, future studies should try to reproduce successive parts of the denture-supporting tissue. We look forward to refining the conditions of this model and realizing an optimal reproduction.

\section{CONCLUSION}

This study proved that it is difficult to estimate elasticity using the thickness of denture-supporting tissue, demonstrated that it is necessary to optimize elasticity at all palatal parts in the FEA, and successfully established a method to measure elasticity.

\section{CLINICAL SIGNIFICANCE}

The 3D FEA simulation is useful for observing the dynamics of denture-supporting tissue while the dentures are in use. However, in creating the basic 3D FEA model, it is critical to optimize the biocompatibility of relevant physical properties, especially the modulus. If it were possible to optimize elasticity in a 3D FEA of maxillary denture-supporting tissue, it would become possible to design an optimal relief area through simulation and reduce burdens on the patient, such as the need for adjustment after wearing dentures, and improve the patient's quality of life.

\section{ACKNOWLEDGMENTS}

The authors would like to thank all of those from the Showa University, Department of Geriatric Dentistry for the cordial supervision received throughout the study, as well as express their gratitude for the helpful advice from Professor Takashi Miyazaki from the Department of Oral Biomaterials and Technology, Professor Kazuyoshi Baba from the Department of Prosthodontics, and Professor Masanori Nakamura from the Department of Oral Anatomy and Developmental Biology.

\section{REFERENCES}

1. Furuya J, Tamada Y, Sato T, Hara A, Nomura T, Kobayashi T, Sakai M, Kondo H. Wearing complete dentures is associated with changes in the three-dimensional shape of the oropharynx in edentulous older people that affect swallowing. Gerodontology 2016 Dec;33(4):513-521.

2. Kydd WL, Daly CH, Wheeler JB 3rd. The thickness measurement of masticatory mucosa in vivo. Int Dent J 1971 Dec;21(4):430-441.

3. Dong J, Zhang FY, Wu GH, Zhang W, Yin J. Measurement of mucosal thickness in denture-bearing area of edentulous mandible. Chin Med J (Engl) 2015 Feb;128(3):342-347.

4. Wara-aswapatiN, Pitiphat W, Chandrapho N, RattanayatikulC, Karimbux N. Thickness of palatal masticatory mucosa associated with age. J Periodontol 2001 Oct;72(10):1407-1412.

5. Sato $S$. The creep of palatal mucoperiostium under various load. J Jpn Prosthodont Soc 1979 Feb;23(1):103-125.[in Japanese]

6. Tsaira A, Karagiannidis P, Sidira M, Kassavetis S, Kugiumtzis D, Logothetidis S, Naka O, Pissiotis A, Michalakis K. Theoretical considerations and a mathematical model for the analysis of the biomechanical response of human keratinized oral mucosa. Front Physiol 2016 Aug;7:364.

7. Chen J, Ahmad R, Li W, Swain M, Li Q. Biomechanics of oral mucosa. J R Soc Interface 2015 Aug;12(109):20150325.

8. Tanaka M, Ogimoto T, Koyano K, Ogawa T. Denture wearing and strong bite force reduce pressure pain threshold of edentulous oral mucosa. J Oral Rehabil 2004 Sep;31(9):873-878.

9. Ogimoto T, Ogawa T, Sumiyoshi K, Matsuka Y, Koyano K. Pressure-pain threshold determination in the oral mucosa: validity and reliability. J Oral Rehabil 2002 Jul;29(7):620-626.

10. Ogawa T, Ogimoto T, Sumiyoshi K, Koyano K. Pressure-pain threshold of oral mucosa and its region-specific modulation by pre-loading. J Oral Rehabil 2003 Nov;30(11):1062-1069. 
11. Ogawa T, Tanaka M, Ogimoto T, Okushi N, Koyano K, Takeuchi K. Mapping, profiling and clustering of pressure pain threshold (PPT) in edentulous oral mucosa. J Dent 2004 Mar;32(3):219-228.

12. Oshima T. Studies on load and strain on the compression of the seat mucosa of complete dentures. Nihon Hotetsu Shika Gakkai Zasshi 1968;12(2):245-291. [in Japanese]

13. Takeuchi S, Sato Y, Sato Y, Kitagawa N, Shimodaira O, Hara S, Isobe A. Measurements of viscoelasticity of oral mucosaestablishing a simultaneous measurement method for load and change of the mucosa thickness. Ann Jpn Prosthodont Soc 2010;2:70-77. [in Japanese]

14. Isobe A, Sato Y, Kitagawa N, Shimodaira O, Hara S, Takeuchi S. The influence of denture supporting tissue properties on pressure-pain threshold-measurement of dentate subjects. J Prosthodont Res 2013 Oct;57(4):275-283.

15. Kotani Y, Sato Y, Kitagawa N, Shimodaira O, Takeuchi S, Isobe A, Takamatsu N, Tanaka S, Hara S. Relationship between palatal mucosa properties and pressure-pain threshold in young dentulous and elderly edentulous subjects. Ronen Shika Igaku 2015 Oct;30(2):68-79.

16. Cheng YY, Cheung WL, Chow TW. Strain analysis of maxillary complete denture with three-dimensional finite element method. J Prosthet Dent 2010 May;103(5):309-318.

17. Lima JB, Orsi IA, Borie E, Lima JH, Noritomi PY. Analysis of stress on mucosa and basal bone underlying complete dentures with different reliner material thicknesses: a three-dimensional finite element study. J Oral Rehabil 2013 Oct;40(10):767-773.

18. Ramakrishnan H, Singh RG. Three-dimensional finite element analysis of the stress distribution pattern in the design modifications of U-shaped palatal major connector. Indian J Dent Res 2010 Oct-Dec;21(4):506-511.

19. Inoue $\mathrm{K}$, Arikawa H, Fujii K, Shinohara N, Kawahata N. Viscoelastic properties of oral soft tissue. 1. A method of determining elasticity of oral soft tissue. Dent Mater J 1985 Jun;4(1):47-53.
20. Ogawa T, Sato Y, Kitagawa N, Nakatsu M. Relationship between retention forces and stress at the distal border in maxillary complete dentures: measurement of retention forces and finite-element analysis in individual participants. J Prosthet Dent 2017 Apr;117(4):524-531.

21. Ishihara H, Kitagawa N, Sato Y, Hara S, Hosono Y, Ishibashi S. A study on the utility of a scale for examination in residual ridge height based on an objective assessment. Nihon Hotetsu Shika Gakkai Zasshi 2007 Oct;51(4):751-759. [in Japanese]

22. Sato Y, Abe Y, Okane H, Tsuga K. Finite element analysis of stress relaxation in soft denture liner. J Oral Rehabil 2000 Aug;27(8):660-663.

23. Omori M, Sato Y, Kitagawa N, Shimura Y, Ito M. A biomechanical investigation of mandibular molar implants: reproducibility and validity of a finite element analysis model. Int J Implant Dent 2015 Dec;1(1):10.

24. Avery, JK. Essentials of oral histology and embryology a clinical approach. 2nd ed. St. Louis (MO): Mosby Inc.; 2000. p. 163.

25. Akimoto K. Observations on the structural changes according to aging of oral mucous membrane in the elderly structure of buccal mucous membrane in the vicinity of angulus oris. Kokubyo Gakkai Zasshi 2004 Jun;71(2):80-94. [in Japanese]

26. Shklar G. The effects of aging upon oral mucosa. J Invest Dermatol 1966 Aug;47(2):115-120.

27. Kohno N. Studies on changes with advancing age in the human gingival. J Kyushu Dent Soc 1975;28:529-558. [in Japanese]

28. Zarb, G.; Bloender, C.; Eckert, S.; Jacob, R.; Fenton, R. Prosthodontic treatment for edentulous patients: complete dentures and implant-supported prostheses. 12th ed. St. Louis (MO): Mosby Inc; 2008. p. 203.

29. Kanbara R, Nakamura Y, Ochiai KT, Kawai T, Tanaka Y. Threedimensional finite element stress analysis: the technique and methodology of non-linear property simulation and soft tissue loading behavior for different partial denture designs. Dent Mater J 2012 Mar;31(2):297-308. 